3. Modi P, Rodriguez E, Hargrove WC, Hassan A, Szeto WY, Chitwood WR. Minimally invasive video-assisted mitral valve surgery: a 12-year, 2-center experience in 1178 patients. J Thorac Cardiovasc Surg. 2009;137:1481-7.

4. Glauber M, Karimov JH. A completely detachable aortic clamping instrument for minimally invasive cardiac surgery. Innovations. 2010;5:309-10.
5. Brown JM, O'Brien SM, Wu C, Sikora JA, Griffith BP, Gammie JS. Isolated aortic valve replacement in North America comprising 108,687 patients in 10 years: changes in risks, valve types, and outcomes in the Society of Thoracic Surgeons National Database. J Thorac Cardiovasc Surg. 2009;137: 82-90.

\title{
Split, in situ left internal thoracic artery to revascularize left anterior descending coronary artery system
}

\author{
Dusko Nezic, MD, PhD, FETCS, Zelimir Antonic, MD, Aleksandar Knezevic, MD, BcS, and \\ Zeljko Bojovic, MD, Belgrade, Serbia
}

The in situ pedicled left internal thoracic artery (LITA) conduit is generally accepted as the coronary artery bypass conduit of choice because of matchless results for its grafting on the left anterior descending (LAD) coronary artery. ${ }^{1}$ Therefore, for carefully selected patients, we have adopted a simple and practical technique of splitting the LITA conduit $^{2}$ and using its proximal and distal parts as in situ arterial grafts to revascularize the LAD coronary artery bed.

\section{CLINICAL SUMMARY}

A 66-year-old man was admitted with progressive postinfarction angina. Hypertension, smoking, hypercholesterolemia, and insulin-dependent type 2 diabetes mellitus were his risk factors for coronary artery disease. Transthoracic echocardiography showed moderately impaired left ventricular function (ejection fraction of 0.35 , with regional inferoposterior and apicolateral akinesia). Angiocardiography revealed triple-vessel disease ( $99 \%$ stenoses of the right coronary artery and its posterior descending branch, a 95\% stenosis of the huge diagonal branch, and an $80 \%$ stenosis of the circumflex coronary artery). The distal part of the occluded LAD was vaguely filled by collaterals from the right coronary artery (Figure 1).

Coronary artery bypass grafting using split, pedicled LITA and vein grafts was planned and accomplished. After full heparinization $(4 \mathrm{mg} / \mathrm{kg})$, the harvested in situ LITA conduit was divided at the junction of the upper two thirds and lower one third. The measured flows of the proximal

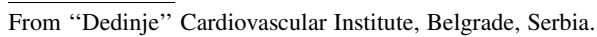

Disclosures: Authors have nothing to disclose with regard to commercial support.

Received for publication March 9, 2011; revisions received May 8, 2011; accepted for publication May 17, 2011; available ahead of print June 27, 2011.

Address for reprints: Dusko Nezic, MD, PhD, FETCS, Chief, Department of Cardiac

Surgery I, "Dedinje" Cardiovascular Institute, M. Tepica 1, 11000 Belgrade,

Serbia (E-mail: nezic@eunet.rs; nezic@ikvbd.com).

J Thorac Cardiovasc Surg 2011;142:1579-80

0022-5223/\$36.00

Copyright (c) 2011 by The American Association for Thoracic Surgery

doi:10.1016/j.jtcvs.2011.05.012 and the distal in situ LITA conduits were $130 \mathrm{~mL} / \mathrm{min}$ and $105 \mathrm{~mL} / \mathrm{min}$, respectively. The proximal LITA was used to revascularize the large diagonal branch, antegradely, in a conventional manner with an end-to-side anastomosis. The distal LITA (supplied by its superior epigastric and musculophrenic branches) revascularized the distal, occluded LAD in a retrograde fashion. Care was taken to anchor the distal LITA pedicle precisely with stay sutures to avoid tension on or kinking of the conduit or anastomosis. Vein grafts anastomoses to the right and circumflex

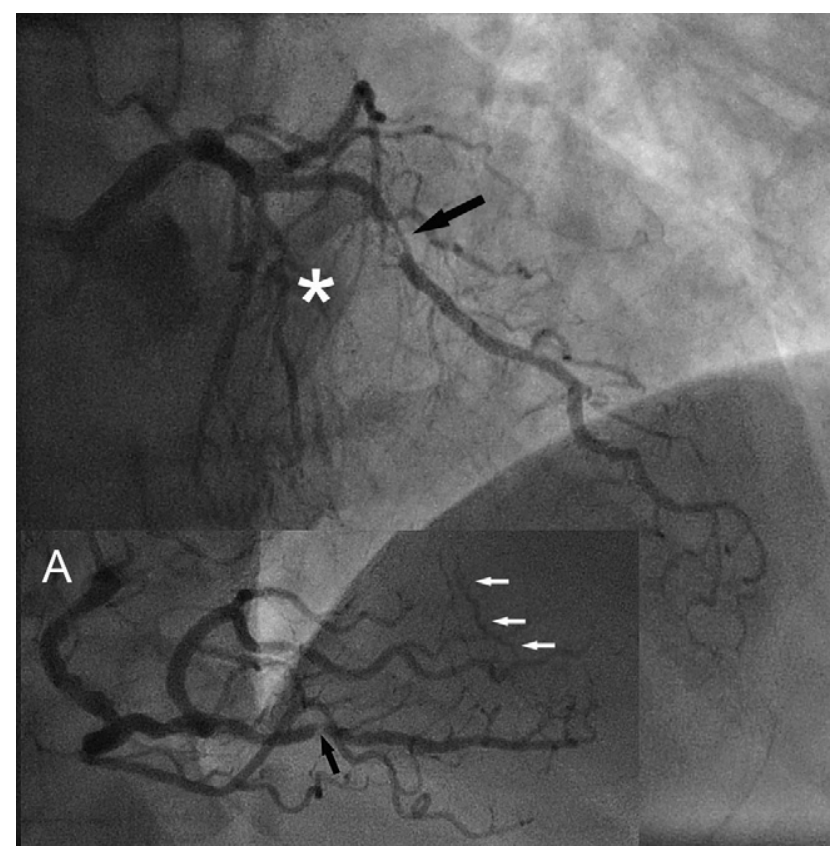

FIGURE 1. Preoperative angiography showed occluded left anterior descending (LAD) coronary artery (white asterisk) and 95\% stenosis of a huge diagonal branch (black arrow). Inset A, Preoperative angiography showed $99 \%$ stenoses of the right coronary artery and its posterior descending branch (black arrow) and the distal part of the occluded LAD that was vaguely filled by collaterals from the right coronary artery (white arrows). 


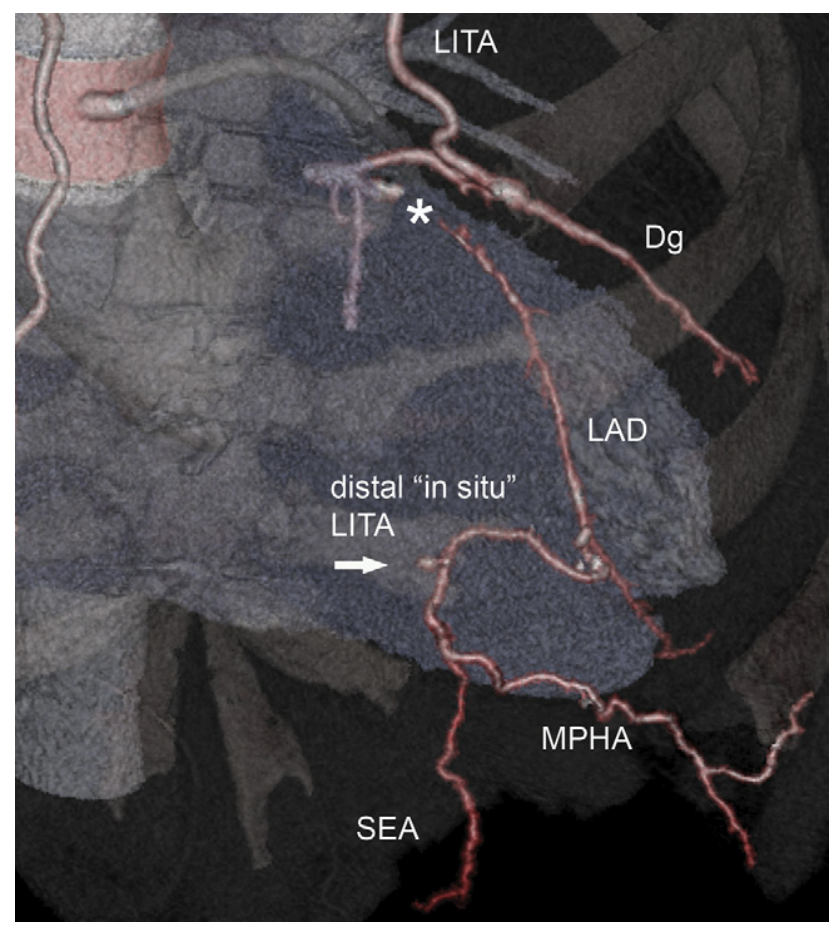

FIGURE 2. A 3-dimensional volume-rendered image with multisegment reconstruction depicts the patent proximal in situ left internal thoracic artery (LITA) attached to the huge diagonal branch $(D g)$ and superior epigastric artery (SEA) and musculophrenic artery (MPHA) with reversed blood flow that supplies the distal in situ LITA remnant (white arrow) and subsequently the left anterior descending ( $L A D)$ coronary artery. White asterisk, The spot of the proximal LAD occlusion.

coronary arteries were performed before LITA anastomoses. The aortic crossclamp time was 39 minutes. The heart returned spontaneously to sinus rhythm, and the patient was weaned easily from cardiopulmonary bypass. On postoperative day 10, a 64-slice multidetector row computed tomographic scan confirmed the perfect patency of the proximal in situ LITA graft, as well as the perfect patency of the distal in situ LITA conduit (supplied by the superior epigastric artery and musculophrenic artery; Figure 2). The patient has been receiving regular follow-up for 1 month and is free of angina with a normal stress test result.

\section{DISCUSSION}

The pedicled internal thoracic artery (ITA) graft is the criterion standard conduit for coronary artery bypass graft surgery, with its superiority as a direct result of its high resistance to atherosclerosis. ${ }^{3}$ Although total arterial revascularization is gaining popularity, skeletonization of the ITA has been advocated as a means of increasing the available graft length for enhanced sequential grafting. However, the skeletonized ITA loses its "milieu," which theoretically (the accumulation of metabolic waste deposits over years) may adversely affect its long-term resistance to atherosclerosis and subsequently its patency rate. ${ }^{3}$ Available studies of long-term patency rates of skeletonized ITAs are not conclusive. ${ }^{4}$ Thus, we prefer to use a pedicled ITA graft because of concerns about whether skeletonization sacrifices longevity.

Although we speculated that the in situ pedicled LITA conduit would not have enough length for sequential bypass, we decided to split it and to use proximal and distal in situ parts as separate conduits to revascularize the LAD coronary artery bed. Von Segesser and colleagues ${ }^{5}$ have considered, in theory, a possible use of the retrograde ITA flow in humans. Their consideration was based on experimental (6 mongrel dogs) data in which canine retro-LITA (LITA transected at its origin [thus supplied by retrograde flow] and then anastomosed to the LAD) delivered significant retrograde flow to completely supress ischemia induced when the canine LAD was ligated. Tutun and colleagues $^{2}$ have used the split LITA technique in 2 patients, and they were able to confirm by Doppler ultrasonography that left superior epigastric artery flow was turned toward the heart. A possible explanation is that arterial flow to the chest and abdominal wall is predominantly systolic and out of phase with the predominantly diastolic coronary circulation. This technique would be applicable in patients in whom the pedicled LITA does not have enough length for sequential grafting (significanly stenosed or occluded LADs that needs to be revascularized near the apex or when a huge diagonal branch is very laterally placed).

To the best of our knowledge, this is the first case in which multidetector row computed tomographic angiography has confirmed reversal of blood flow from superior epigastric and musculophrenic arteries that supply the "in situ" distal part of the LITA and subsequently the LAD.

\section{References}

1. Nasso G, Coppola R, Bonifazi R, Piancone F, Bozzetti G, Speziale G. Arterial revascularization in primary coronary artery bypass grafting: direct comparison of 4 strategies-results of the Stand-in-Y Mammary Study. J Thorac Cardiovasc Surg. 2009;137:1093-100.

2. Tutun U, Cicekcioglu F, Parlar I, Tola M, Ulus T, Katircioglu F. A new technique for the old arterial graft: internal thoracic artery. J Card Surg. 2008;23:159-62.

3. Del Campo C. Pedicled or skeletonized? A review on the internal thoracic artery graft. Tex Heart Inst J. 2003;30:170-5.

4. Ali E, Saso S, Ashrafian H, Athanasiou T. Does a skeletonized or pedicled left internal thoracic artery give the best graft patency? Int Cardiovasc Thorac Surg. 2010;10:97-104.

5. von Segesser L, Lehmann K, Turina M. Retrograde internal mammary to coronary artery anastomoses. Thorac Cardiovasc Surg. 1989;37:143-6. 